\title{
A comparative study of particle size distribution using analysis of variance for sedimentation and laser diffraction methods
}

\author{
(Estudo comparativo de análise de distribuição de tamanho \\ de partículas através da análise de variância para os métodos \\ de sedimentação e difração a laser)
}

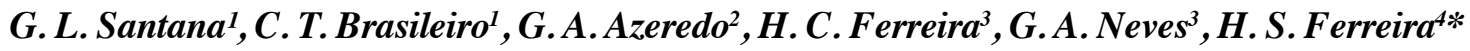 \\ ${ }^{1}$ Federal University of Paraíba, Graduate Program in Materials Science and Engineering, João Pessoa, PB, Brazil \\ ${ }^{2}$ Federal University of Paraíba, CT, Civil Engineering Department, João Pessoa, PB, Brazil \\ ${ }^{3}$ Federal University of Campina Grande, CCT, Materials Engineering Department, Campina Grande, PB, Brazil \\ ${ }^{4}$ Federal University of Paraíba, CT, Materials Engineering Department, 58051-900, João Pessoa, PB, Brazil
}

\begin{abstract}
The granulometric analysis is a basic tool in the characterization process of particulate materials and can be determined through numerous methods, most notably the densimeter and laser diffraction methods. However, these techniques are based on distinct physical principles that can generate different results causing doubts. The objective of this paper was to study both methods, using a standardized sample preparation according to Brazilian standard NBR 7181. Kaolin and quartz samples were used to represent the clayey and sandy soil fractions, respectively, with compositions varying from $100 \%$ to $0 \%$ kaolin content. Granulometric distribution curves and respective fractions of each composition were determined. These results were statistically compared by analysis of variance (F-test) and correlated using linear regression. The statistical comparison indicated a strong dependence between the densitometer and laser diffraction methods with and without the same sample preparation, indicating a direct correlation with $95 \%$ confidence. Keywords: particle size distribution, sedimentation, density, laser diffraction.
\end{abstract}

\section{Resumo}

A análise granulométrica é uma ferramenta básica no processo de caracterização de materiais particulados, podendo ser obtida por vários métodos, destacando-se os métodos do densímetro e difração a laser. No entanto, estas técnicas são baseadas em princípios físicos distintos, que geram resultados diferentes, causando dúvidas. O objetivo deste trabalho foi estudar ambos os métodos com a uniformização da preparação de amostras seguindo a norma brasileira (NBR 7181). Amostras de caulim e quartzo foram utilizadas para representar as frações argilosa e arenosa do solo, respectivamente, com composições variando de $100 \%$ a $0 \%$ de teor de caulim, obtendo curvas de distribuição granulométrica e respectivas frações de cada composição. Esses resultados foram comparados estatisticamente por análise de variância (teste $F$ ) e correlacionados por meio de regressão linear. A comparação estatística indicou uma forte dependência entre os métodos do densímetro e difração a laser com e sem a preparação da amostra, indicando uma correlação direta com $95 \%$ de confiança.

Palavras-chave: distribuição do tamanho de partícula, sedimentação, densímetro, método de difração a laser.

\section{INTRODUCTION}

The study of particle size and their distribution are of paramount importance for determining the properties of particulate materials. Particle size analysis for solid particles consists of determining the frequency with which particles occur in given size classes or ranges. The problem in this type of characterization is the result of the wide range of techniques available to obtain the particle size and its distribution [1]. The techniques for determining the particle size distribution for particulate systems are classified based

*hebersivini@gmail.com

(D) https://orcid.org/0000-0003-1992-4089 on the fraction types. The granulometry of the coarse fractions (larger than the ABNT $2000.074 \mathrm{~mm}$ sieve) is carried out by direct measurement through sieving. For the fine fractions (smaller than the $0.074 \mathrm{~mm}$ sieve), the granulometry is performed by both direct and indirect measurement. The direct method uses microscopic evaluation while the indirect methods are based on the relationship between particle size and a physical property, as in the sedimentation methods using Stokes' law and diffraction methods (laser, X-ray and optical), where the data treatments are performed by means of specific algorithms to each technique [2].

The densimeter method is a technique based on sedimentation governed by Stokes' law, which relates the size of the particle to the sedimentation velocity in a liquid 
medium. When the height of fall $(\mathrm{H})$ and the settling time $(\mathrm{t})$ are known, the particle diameter (D) can be found. A particle falls due to the force of gravity in any fluid medium and during its movement is subject to a resistive force, whose magnitude depends on the fluid-dynamic regime and the morphological aspects of the particle. When the resistive forces (thrust and friction) equalize with the force of gravity, the particle reaches its terminal velocity, also known as sedimentation velocity, and falls at a constant rate $[1,3]$. As studies have advanced, methods based on Stokes' law were joined with laser diffraction. Later, equipment began to use only laser diffraction to obtain the size and distribution of particles. The laser diffraction technique is very efficient and quickly returns results using the angular variation caused in the intensity of the incident light as the beam interacts with the particles dispersed in a fluid. The incident beam interacts with the particles in four distinct ways (diffraction, refraction, reflection, and absorption), forming a three-dimensional light envelope, which is affected by the optical properties (relative refractive index of the particle in the dispersing medium), the length of the light wave, and by the size and shape of the particle. Detectors measure the intensity and angle of the scattered light, generating a signal that is then converted into a particle size distribution using mathematical algorithms. This creates the scattering pattern, which can be analyzed based on Mie's diffusion theory of light, knowing the refractive indexes of the material and the environment medium $[1,4]$.

Because each technique uses different physical principles for its analysis, the numerical values obtained are distinct from each other, making studies that correlate these values to find a common result necessary. Furthermore, there are striking differences between the dispersion methods and the preparation of the sample used, due to this the standardization of the granulometric analysis methods is of great interest in order to facilitate the interpretation of data obtained by different research areas $[5,6]$. With regard to dispersion, the conventional sodium hexametaphosphate is specified in the Brazilian standard NBR7181 as the dispersant indicated for use in the densimeter method. During particle size and distribution analysis, the system should be completely dispersed, and this depends on the type of material being evaluated and the concentration of dispersant used. The fixed content of the dispersant defined by the standard can create a problem when its value is insufficient to promote the deagglomeration of all of the particles in the studied material. On the preparation of the sample, in turn, the physical characteristics of the material and the dispersion properties may affect the final result of the analysis, such as sample type and size, degree of aggregation, dispersion, type and concentration of the dispersing agent, $\mathrm{pH}$, and zeta potential. These variables should be considered in the analysis in order to achieve a correlation between the results of the different granulometric analysis techniques presented in this work [7]. The objective of this study was to compare different methods of granulometric analysis, with the standardized sample preparation according to the Brazilian standard NBR 7181, through the analysis of variance by the F-test.

\section{MATERIALS AND METHODS}

The samples used were composed of kaolin and quartz, for the purpose of representing the composition of the fine soil fraction (passing through sieve \#200), where the kaolin represented the clay fraction and the quartz the sandy fraction. The materials were obtained from Armil Minérios, for which five different formulations described in Table I were studied. The formulations were characterized by X-ray diffraction (XRD 6000, Shimadzu) to identify crystal phases present, where the radiation used was $\mathrm{K} \alpha$ of $\mathrm{Cu}, 2 \theta$ angle ranging from $5^{\circ}$ to $60^{\circ}$ and step scan of $0.02^{\circ}$. The identifications were made with X'pert HighScore Plus 3.0 software and its database. The thermal analysis (TA $60 \mathrm{H}$, Shimadzu) was performed starting at the room temperature up to $1000{ }^{\circ} \mathrm{C}$, with a heating rate of $12.5^{\circ} \mathrm{C} / \mathrm{min}$. The chemical composition was determined by $\mathrm{X}$-ray fluorescence spectroscopy (FRX 1800, Shimadzu). For granulometric analysis, sedimentation and laser diffraction techniques were used.

Table I - Description of formulations containing kaolin and quartz.

[Tabela I - Descrição das formulações contendo caulim e quartzo.]

\begin{tabular}{cc}
\hline Sample & Composition (wt $\%)$ \\
\hline QUARTZ & $100 \%$ quartz \\
CAU25 & $25 \%$ kaolin $+75 \%$ quartz \\
CAU50 & $50 \%$ kaolin $+50 \%$ quartz \\
CAU75 & $75 \%$ kaolin $+25 \%$ quartz \\
CAU100 & $100 \%$ kaolin \\
\hline
\end{tabular}

Dispersions were prepared for the granulometric analysis following the procedure described in NBR 7181-84 [8], in which $100 \mathrm{~g}$ of the formulation was added to $125 \mathrm{~mL}$ of sodium hexametaphosphate solution with a concentration of $45.7 \mathrm{~g}$ of salt per liter of water. The dispersion was kept at rest for $24 \mathrm{~h}$ and then stirred for $15 \mathrm{~min}$. It was then transferred to a beaker until the filling of $1 \mathrm{~L}$; at this time the sedimentation test began. In the densimeter, the exact time which sedimentation began was recorded, and then the corresponding sedimentation times $(t)$ of $0.5,1$, and $2 \mathrm{~min}$ were recorded (it is recommended to repeat these three first data after stirring the dispersion again, redoing them with the same initial times). The records were made subsequently at $4,8,15$, and $30 \mathrm{~min}$, and then at 1, 2, 4, 8 , and $24 \mathrm{~h}$ of sedimentation. After preparation, $10 \mathrm{~mL}$ of the dispersion was removed for the particle size analysis by laser diffraction (Cilas, 1090, particle size analyzer). The measurement was based on Mie and Fraunhofer scattering theories with detected size range from 0.04 to $500 \mu \mathrm{m}$, obscuration index of $20 \%$ and ultrasonication by $60 \mathrm{~s}$. Analyses were also carried out without the described sample preparation, for purposes of comparison. In summary, the granulometric analysis methods used in this research are 
described as sedimentation method (densimeter), laser with sample preparation (LPP) and laser without sample preparation (LP).

In order to evaluate whether or not there were significant differences between the results obtained from the granulometric distribution analysis techniques, statistical analysis of variance was used to verify the difference between the means of two or more populations, based on the concept of standard deviation for each sample, the square of which results in the variance. This type of analysis can be considered an indicator of the behavior of the variables of two groups in order to differentiate between them. The hypotheses H0 (null hypothesis) and $\mathrm{H} 1$ (alternative hypothesis) related to the difference between the two variances are defined by the researcher. The null hypothesis, initially considered true, considers the variances of the two populations (S1 and S2) are equal and before its validation it is necessary to define the level of significance of the test $(\alpha)$ established in $5 \%$ in this research; from this, the confidence interval of the test (1- $\alpha)$ and its critical values were obtained. To test them, the $F$ value was calculated from the ratio of the sample variances obtained from independent samples of the two populations, and then compared with the tabulated $\mathrm{F}$ value, obtained from the Fisher-Snedecor distribution at the $95 \%$ of confidence, defined as limits of the region of acceptance or rejection of the null hypothesis. If the calculated F is less than the table $\mathrm{F}$, it is inside the acceptance region and the null hypothesis is accepted, indicating that there is no statistically significant difference between the variances of both populations; otherwise, the null hypothesis is rejected, indicating a statistically significant difference between the populations. To quantify the degree of correlation between the two methods under analysis, a linear regression was performed using the results obtained in the previously-described assays in order to determine the correlation coefficients. Pearson's correlation coefficient (R) was obtained by dividing the covariance of two variables by the product of their standard deviations, where in this case the variables examined were the cumulative volume percentage data for each method. The limit values of $\mathrm{R}$ are -1 and +1 . The closer the unit is to its module, the greater the linear dependence between the variables involved. There is a conventional correlation classification defined in the literature that determines the level of correlation by the coefficient, so that $|r|=1$, the correlation is perfect [9]. The coefficient of determination, in turn, is defined by the value of the Pearson coefficient squared $\left(\mathrm{R}^{2}\right)$, and establishes in a percentage degree the fit quality of a model, indicating how well it was able to explain the obtained results, as the module approaches the unit.

\section{RESULTS AND DISCUSSION}

\section{Characterization of formulations}

In Fig. 1, the X-ray diffractograms for the compositions under study are shown. It was possible to observe the decrease of the characteristic kaolinite peaks in relation to the quartz peaks, as the kaolin content was reduced. The characteristic peaks of kaolinite clay of highest intensities are highlighted and are located at positions $12.48^{\circ}$ and $25.00^{\circ}$, with interplanar distances of 7.09 and $3.56 \AA$, expected because kaolin is a material formed by a group of hydrated aluminum silicates, mainly kaolinite [10]. In addition to kaolinite, it was possible to verify the presence of muscovite mica as a contaminant present in compositions CAU100, CAU75, and CAU50, with characteristic peaks at $2 \theta 8.99^{\circ}$ and $17.88^{\circ}$, corresponding to distances of 9.83 and $4.96 \AA$, respectively. The characteristic peaks of quartz with the highest intensities are located at $2 \theta$ positions of $26.78^{\circ}$ and $21.02^{\circ}$, with interplanar distances of 3.32 and $4.22 \AA[11,12]$. Table II shows the chemical composition of the formulations under study, as determined using X-ray fluorescence spectroscopy. The CAU100 composition had $\mathrm{SiO}_{2}$ and $\mathrm{Al}_{2} \mathrm{O}_{3}$ contents of $57.18 \%$ and $28.21 \%$, respectively, which differed from those found in the literature for theoretical kaolinite, $39.8 \%$ and $46.5 \%$, respectively. This occurred due to the presence of silicates that may be derived from clay minerals, mica, or feldspar present as contaminants in the composition. In this case, the contaminant was mica, as determined by the diffraction results. With the increase of quartz in the composition, the silica content increased considerably, decreasing the relative concentration of alumina. This was due to the chemical composition of quartz being composed exclusively of silica [11]. Fig. 2 represents the thermal behavior of the formulations under study. The decrease in the percentage of mass loss as the quartz content increased can be clearly seen, as quartz is a material of high thermal stability. The kaolin, in turn, is formed mainly by the clay mineral kaolinite, defined as a group of hydrated aluminum silicates, confirmed through XRD. The presence of water molecules, both adsorbed and in the composition, was eliminated by the increase in temperature, explaining the higher mass loss percentages for compositions having higher kaolin content. For compositions CAU100, CAU75, CAU50, CAU25 and QUARTZ, the mass losses were $12.63 \%, 8.20 \%$, $3.57 \%, 1.67 \%$, and $0.00 \%$ respectively. These were similar to the results found in the literature [13].

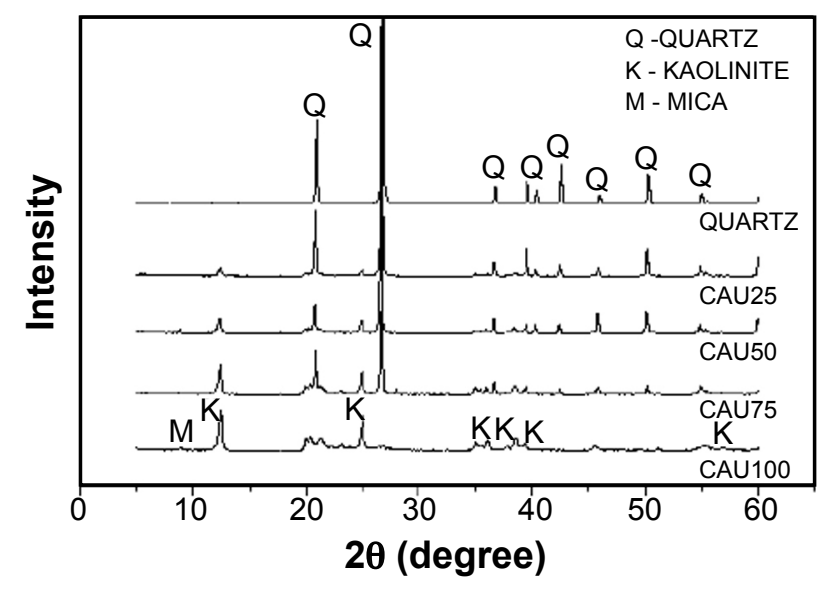

Figure 1: X-ray diffraction pattems of the studied compositions. [Figura 1: Difratogramas de raios $X$ das composições em estudo.] 
Table II - Chemical composition (\% by mass) of the compositions used in this study.

[Tabela II - Composição química (\% em massa) das composições utilizadas neste estudo.]

\begin{tabular}{cccccccccc}
\hline Sample & LOI & $\mathrm{SiO}_{2}$ & $\mathrm{Al}_{2} \mathrm{O}_{3}$ & $\mathrm{~K}_{2} \mathrm{O}$ & $\mathrm{Fe}_{2} \mathrm{O}_{3}$ & $\mathrm{MgO}$ & $\mathrm{Na}_{2} \mathrm{O}$ & $\mathrm{CaO}$ & Others \\
\hline CAU100 & 11.98 & 57.18 & 28.21 & 1.02 & 0.98 & 0.18 & 0.13 & 0.08 & 0.21 \\
CAU75 & 9.25 & 65.40 & 23.21 & 0.83 & 0.72 & 0.14 & 0.16 & 0.07 & 0.18 \\
CAU50 & 8.33 & 73.05 & 17.13 & 0.54 & 0.47 & 0.12 & 0.11 & 0.05 & 0.10 \\
CAU25 & 2.86 & 87.26 & 9.00 & 0.30 & 0.25 & 0.08 & 0.13 & 0.05 & 0.05 \\
QUARTZ & 1.64 & 97.71 & 0.30 & 0.06 & 0.08 & 0.00 & 0.15 & 0.04 & 0.00 \\
\hline LOI- loss on ignition. & & & & & & & &
\end{tabular}

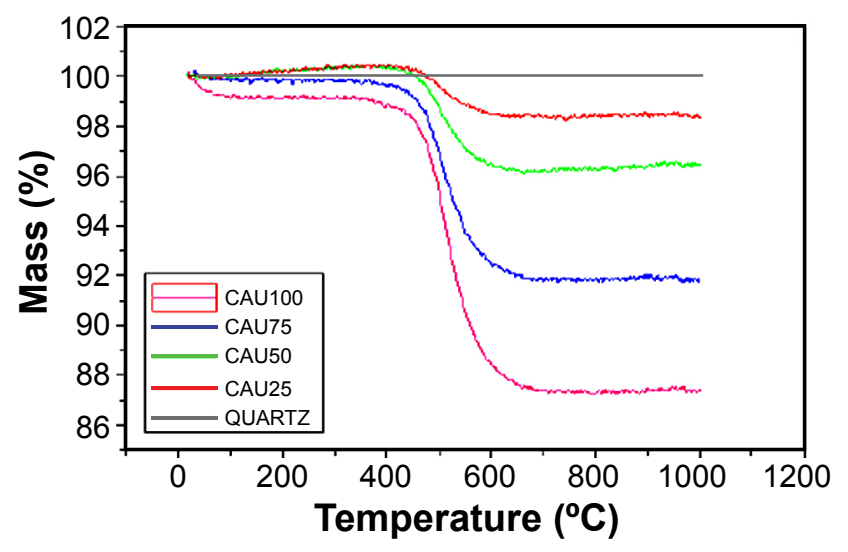

Figure 2: Thermal behavior of the compositions under study (thermogravimetric analysis).

[Figura 2: Comportamento térmico das composições em estudo (análise termogravimétrica).]

The results obtained from the sedimentation test are shown in Tables III and IV; the granulometric distribution curves are shown in Figs. $3 \mathrm{a}$ and $3 \mathrm{~d}$. It was possible to see that the cumulative volume curves were discontinuous at the first point of the densimeter analysis, $74 \mu \mathrm{m}$. Similar results have been reported in the literature $[14,15]$. Some authors have noted several factors that contribute to this discontinuity in the granulometric distribution curves, the main one is the change in the flow pattern of the suspension. During the initial stage of analysis, the suspension was agitated to maintain homogeneity and to prevent deposition of material at the bottom of the cylinder. This caused the movement of the particles chaotic and irregular, making Stokes's law no longer applicable. This turbulent flow can last for several minutes, affecting the initial readings of the densimeter, and therefore the curve [15]. It is important to note in Table III that it was not possible to identify the $10 \%$ particle diameter (D10) for the compositions under study in the densimeter method. The density of a suspension is proportional to the amount of solid present and to the difference between the densities of the suspending liquid and the suspended solid. The density of the suspension was measured from the densimeter recordings performed at predefined times and may have been insufficient to drop of minor diameter particles, as also the measurement was limited by the resolution of the equipment used to obtain the data [16]. It has been shown that the results obtained for the particle size distribution are strongly affected by the shape of the particles. This phenomenon causes the sedimentation velocity of the particles to be smaller than the sphere velocity with the same volume, where particles with flat shape tend to sediment not in a straight line, but describing an oscillating trajectory $[1,17]$. The results obtained from the laser diffraction test using samples prepared according to the procedure of NBR 7181-84 are shown in Tables III and IV; the granulometric distribution curves are shown in Figs. $3 \mathrm{~b}$ and $3 \mathrm{e}$. Tables III and IV also show the results obtained by the laser diffraction test without the ABNT standardized sample preparation; the grain size distribution curves are

Table III - Particle diameters by densimeter, LPP and LP methods.

[Tabela III - Diâmetros de partículas pelos métodos do densimetro, LPP e LP.]

\begin{tabular}{ccccc}
\hline Sample & $\begin{array}{c}\text { D10 } \\
(\mu \mathrm{m})\end{array}$ & $\begin{array}{c}\text { D50 } \\
(\mu \mathrm{m})\end{array}$ & $\begin{array}{c}\text { D90 } \\
(\mu \mathrm{m})\end{array}$ & $\begin{array}{c}\mathrm{D}_{\mathrm{v}} \\
(\mu \mathrm{m})\end{array}$ \\
\hline \multicolumn{5}{c}{ Densimeter method } \\
CAU100 & $*$ & 2.60 & 19.11 & 9.82 \\
CAU75 & $*$ & 3.72 & 65.55 & 11.76 \\
CAU50 & $*$ & 10.07 & 70.36 & 11.19 \\
CAU25 & $*$ & 23.63 & 70.36 & 11.62 \\
QUARTZ & 2.79 & 46.01 & 72.19 & 11.18 \\
\hline \multicolumn{5}{c}{ LPP method } \\
CAU100 & 1.34 & 6.04 & 37.87 & 12.78 \\
CAU75 & 0.89 & 3.29 & 14.74 & 6.24 \\
CAU50 & 1.48 & 7.75 & 38.96 & 14.20 \\
CAU25 & 1.41 & 5.95 & 23.42 & 9.48 \\
QUARTZ & 2.03 & 11.27 & 38.70 & 16.15 \\
\hline \multicolumn{5}{c}{ LP method } \\
CAU100 & 2.13 & 11.20 & 46.64 & 17.94 \\
CAU75 & 2.22 & 11.44 & 62.61 & 22.95 \\
CAU50 & 2.17 & 12.55 & 64.02 & 23.64 \\
CAU25 & 2.44 & 18.12 & 79.30 & 31.07 \\
QUARTZ & 3.39 & 30.27 & 91.52 & 39.90 \\
\hline
\end{tabular}

* - no data due to equipment resolution [symmetrical bulb soil densimeter (0.995/1.050 g/ $\left.\mathrm{cm}^{3}\right)$ according to NBR 7181]; D10, D50, D90 - 10\%, 50\%, $90 \%$ particle diameter, respectively; $D v$ - average particle diameter. 
Table IV - Clay, silt, and sand fractions (\%) by densimeter, LPP and LP methods.

[Tabela IV - Frações argila, silte e areia (\%) pelos métodos do densimetro, LPP e LP.]

\begin{tabular}{|c|c|c|c|}
\hline Sample & Clay $^{1}$ & Silt $^{2}$ & Sand $^{3}$ \\
\hline \multicolumn{4}{|c|}{ Densimeter method } \\
\hline CAU100 & 43.41 & 56.42 & 0.17 \\
\hline CAU75 & 36.14 & 45.15 & 18.71 \\
\hline CAU50 & 27.66 & 43.14 & 29.20 \\
\hline CAU25 & 18.37 & 48.82 & 32.81 \\
\hline QUARTZ & 7.49 & 48.36 & 46.15 \\
\hline \multicolumn{4}{|c|}{ LPP method } \\
\hline CAU100 & 17.98 & 79.82 & 2.20 \\
\hline CAU75 & 27.96 & 71.87 & 0.18 \\
\hline CAU50 & 15.52 & 82.67 & 1.81 \\
\hline CAU25 & 17.04 & 82.79 & 0.17 \\
\hline QUARTZ & 9.76 & 88.86 & 1.38 \\
\hline \multicolumn{4}{|c|}{ LP method } \\
\hline CAU100 & 9.12 & 86.54 & 4.34 \\
\hline CAU75 & 8.56 & 80.80 & 10.64 \\
\hline CAU50 & 8.86 & 79.63 & 11.51 \\
\hline CAU25 & 7.48 & 74.71 & 17.81 \\
\hline QUARTZ & 4.97 & 68.67 & 26.36 \\
\hline
\end{tabular}

${ }^{1}-d<2 \mu m ;^{2}-2<d<60 \mu m ;^{3}-60<d<200 \mu m$. shown in Figs. 3c and $3 \mathrm{f}$.

The results and curves obtained by these methods were compared and the difference between the results found was statistically evaluated. Fig. 4 shows the cumulative volume curves obtained by the methods for each formulation used. The differences between the granulometric curves generated by each method directly influenced the differences in the textural classification of the compositions, that is, in the clay, silt, and sand fractions. By comparing the results of the textural classification from the laser diffraction methods with and without sample preparation, an underestimation of the clay fraction for the unprepared sample method was seen. This showed that pretreatment is important because it breaks down the clay microaggregates, reducing error in the overestimation of the silt fraction, characteristic of the laser equipment. However, it was still not enough for the methods to produce equivalent results. These effects were also verified in the literature $[15,18-20]$. With regard to the differences in textural classification obtained from the densimeter and laser diffraction methods, for all compositions, the clay fraction measured by laser diffraction was underestimated, even when using the same sample preparation for both techniques. This was due to the difference between the method of obtaining the equivalent diameter that each technique employs. Laser diffraction measured the optical grain diameter and from this, determined the equivalent spherical diameter. However, clay minerals have elongated particles with a high aspect ratio (diameter/thickness), hence the optical diameter obtained was larger than the equivalent spherical diameter, meaning that a considerable portion of the material measured as clay
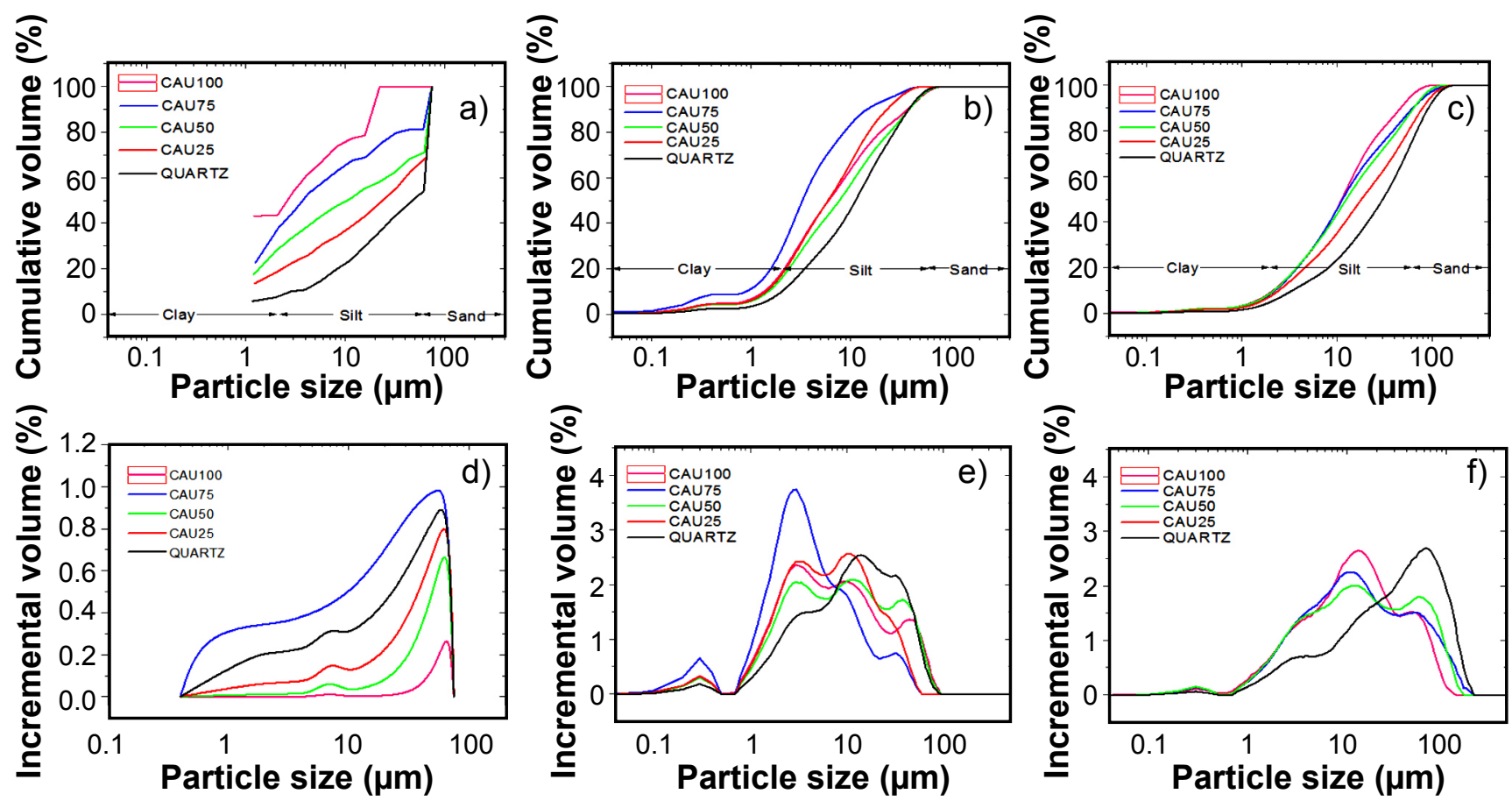

Figure 3: Granulometric distribution curves by densimeter (a,d), LPP (b,e), and LP (c,f) methods: a-c) cumulative volume; and d-f) incremental volume.

[Figura 3: Curvas de distribuição granulométrica pelos métodos do densímetro (a,d), LPP (b,e) e LP (c,f): a-c) volume cumulativo; e d-f) volume incremental.] 
by the densimeter was measured as silt by laser diffraction. These results were comparable to those found in the literature $[15,18,21]$. Some authors have pointed out that these methods have a high degree of agreement regarding the sand fraction of soils, as the particles of this fraction are practically spherical $[15,19,20]$. However, this agreement was not seen in this study, with the difference attributed to the size of the quartz particles. These particles, which represented the sandy fraction of the soil, passed through a \#200 mesh sieve and were therefore within the size range considered to be clay fraction, possibly confusing the equipment and generating an error in the determination of the sand fraction. This may be characterized as a limitation of the laser diffraction technique.

The granulometric analysis is frequently used in the study of soils to determine the granulometric fractions, which are described based on particle size. However, the categorization of particle size for each fraction can lead to errors in soil classification. Because specific materials were used to prepare the formulations, it was possible to know their mineralogical characteristics in advance and to limit the size range used (\#200 mesh). By comparing the results obtained from the different techniques under study, it was possible to observe that the sample of kaolin, strictly clay, was shown to have a silt and sand fraction (added together) larger than its clay fraction. The quartz sample, strictly sandy, was shown to have a clay and silt fraction (added together) larger than its sand fraction, for all techniques used in this study. Among these methods, the densimeter technique produced percentage values for each fraction closest to the actual composition for each prepared formulation. This confirmed the low ability of the methods under study to deagglomerate the grains and therefore a low representativity, which can lead to errors in soil classification. The laser diffraction technique presented advantages over the densimeter method, such as: 1) it is quick to perform and provides more detailed information; 2) it has better reproducibility; and 3) it requires only small sample amounts. However, it was not able to measure the clay, silt, and sand fractions with high accuracy, such that for the composition composed only of kaolin (CAU100), high values related to the silt and sand fractions were identified (without sample preparation). Variations in density, particle shape, and mineralogy of the sand, silt, and clay ranges are the main factors that lead to the differences found [22]. However, in this study, known materials were used for the different compositions in order to eliminate any possible differences in density, shape, and mineralogy of the particles, and even so, differences were observed between the textural classification of the compositions obtained by the different methods, reinforcing the assertion that the differences between the physical principles that govern each method are the major causes of the inequal results obtained. In general, there is no universal correlation between the granulometric analysis methods, so a study of these correlations is necessary to verify the applicability of each technique.

\section{Correlations}

Correlation analysis between densimeter and LPP methods: Fig. 5 shows the correlation between the cumulative volume obtained by the densimeter method
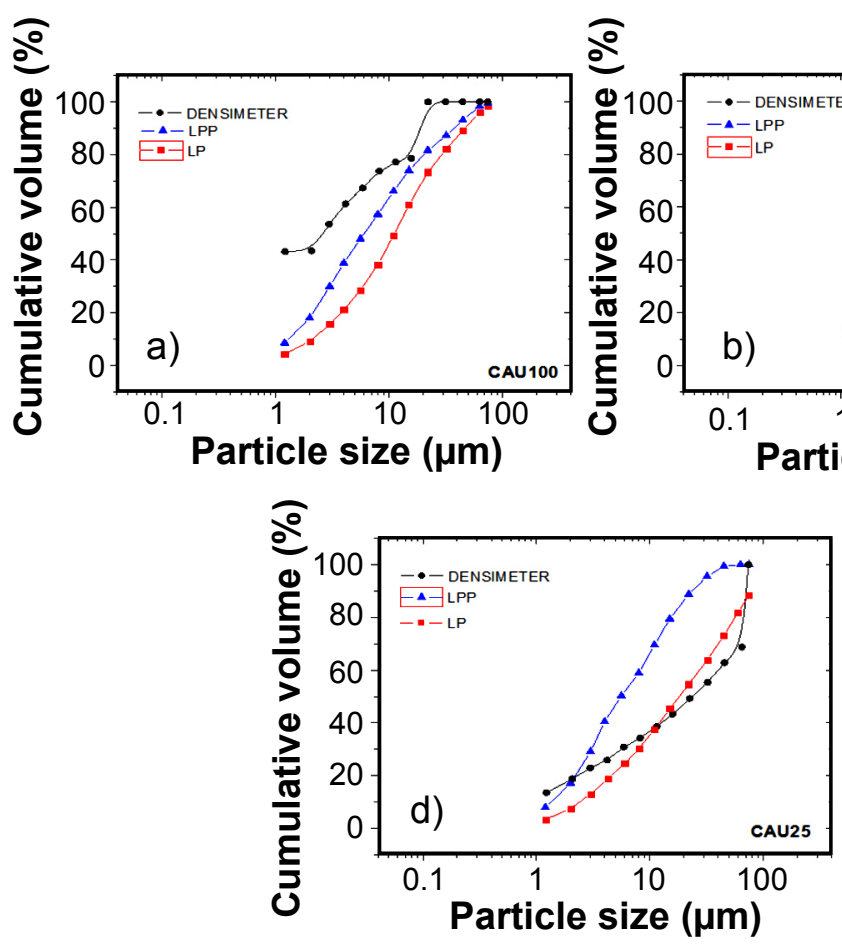
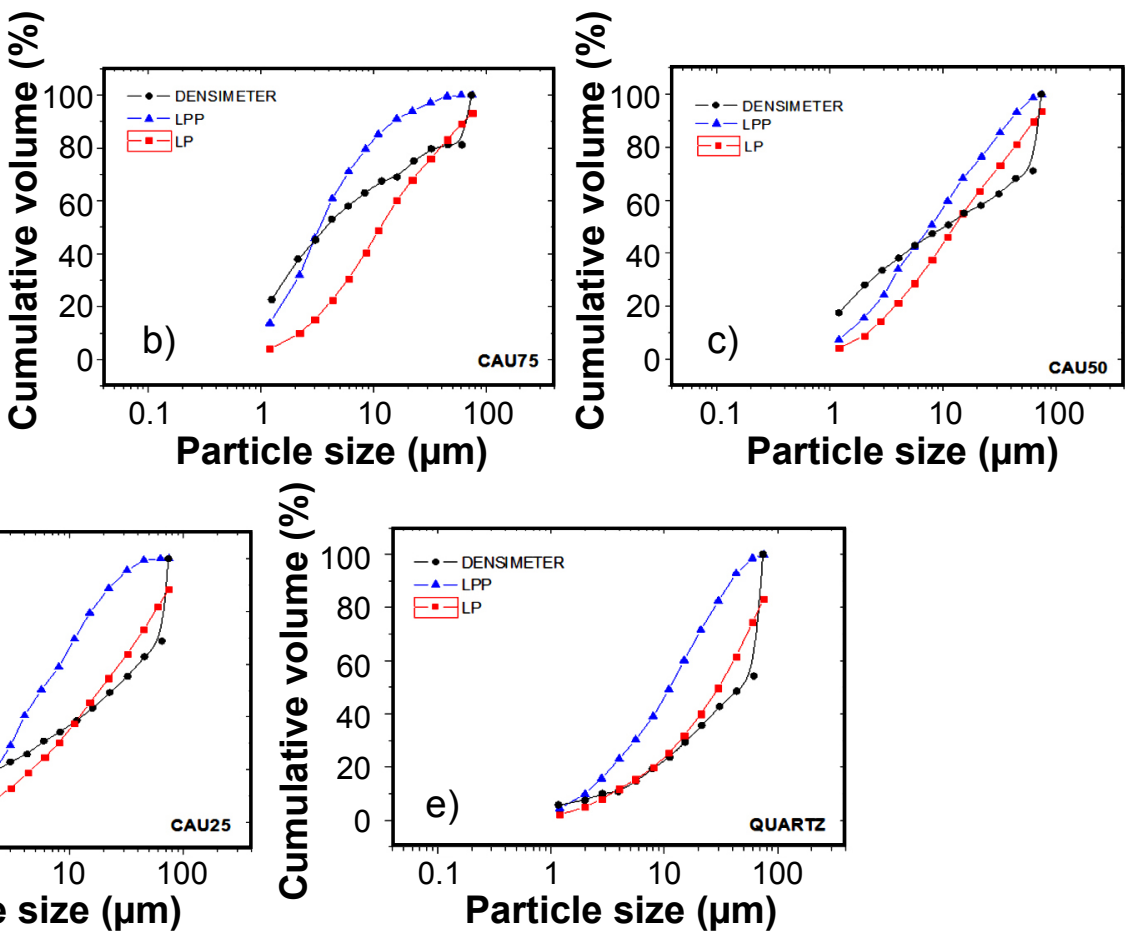

Figure 4: Cumulative particle size distribution curves obtained from each method studied for each composition. [Figura 4: Curvas da distribuição cumulativa do tamanho das partículas obtidos pelos métodos em estudo para cada composição.] 

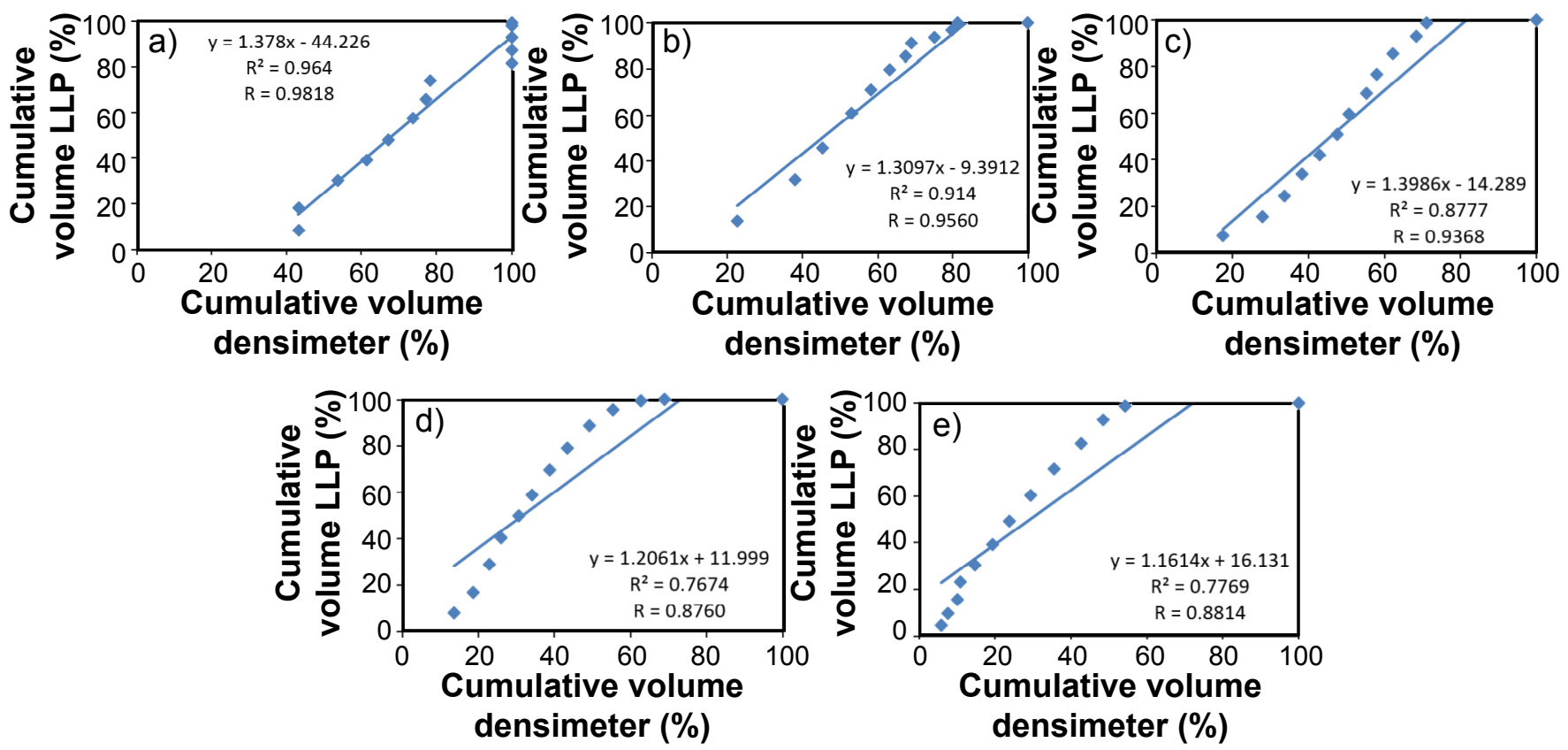

Figure 5: Correlation graph between densimeter and LPP methods: a) CAU100; b) CAU75; c) CAU50; d) CAU25; and e) QUARTZ.

[Figura 5: Gráfico de correlação entre os métodos do densímetro e LPP: a) CAU100; b) CAU75; c) CAU50; d) CAU25; e e) QUARTZO.]

and the cumulative volume obtained by the LPP method. Accordingly, the coefficient of determination $\mathrm{R}^{2}$ assured the adjustment quality of the model for all formulations under study. The correlation coefficient $\mathrm{R}$ for compositions CAU100 and CAU50 indicated a very strong relationship between the variables under analysis, and for compositions CAU75, CAU25, and QUARTZ the relationship between the variables was strong, as indicated by the coefficients obtained. These results fit with the comparisons between the granulometric curves previously described, since with the preparation of the sample, deagglomeration of the clay microaggregates occurred, and this facilitated the detection of the clay particles by the laser diffraction method. It was, therefore, possible to see that the results obtained by both techniques were similar for cumulative volumes, especially for materials composed predominantly of clay. For each technique alone, the cumulative volume is a function of particle size, that is, for each size range, a particle volume of that size was obtained during the test.

Correlation analysis between LPP and LP methods: Fig. 6 shows the results of the correlation between the cumulative volume obtained from the laser diffraction method when the sample was prepared or not according to NBR 7181-84. Accordingly, the coefficient of determination $\mathrm{R}^{2}$ assured the quality of the model fit for all formulations, just as the correlation coefficient $\mathrm{R}$ indicated a very strong relation
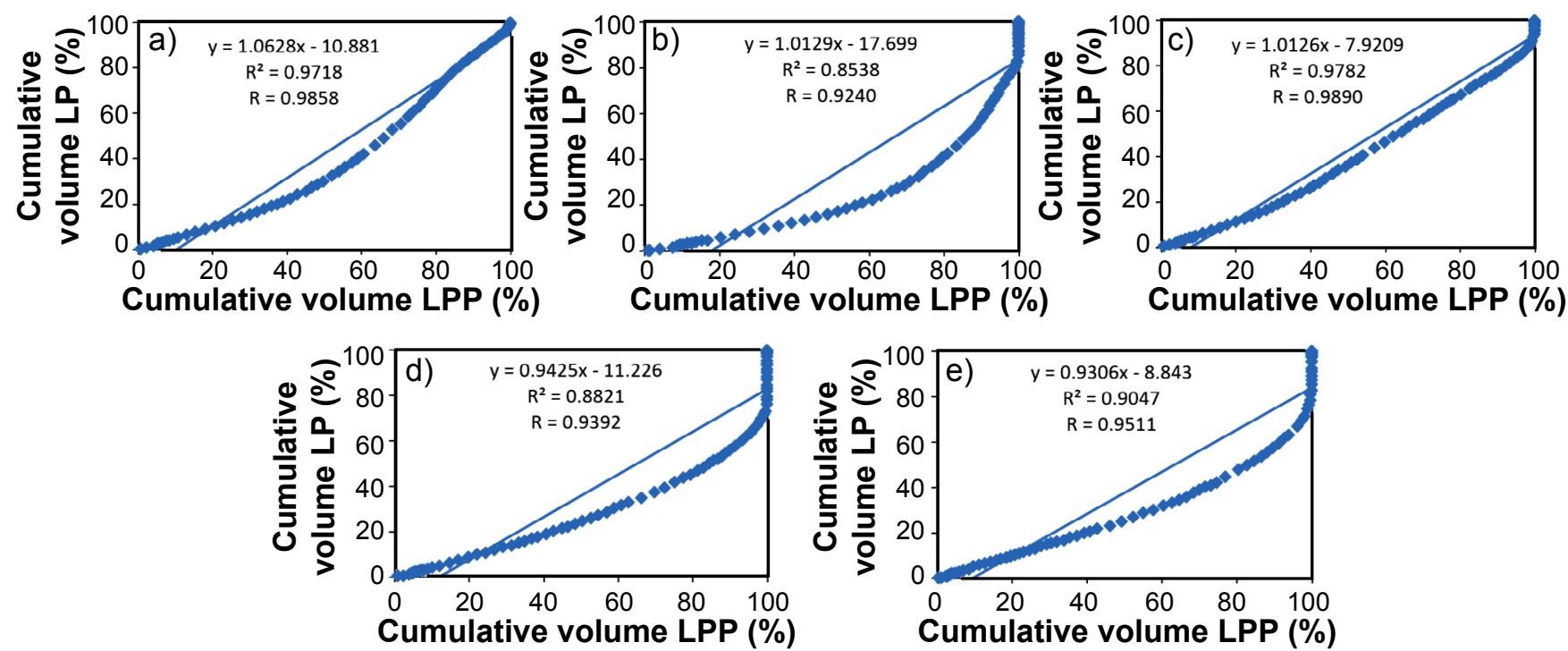

Figure 6: Correlation between the laser diffraction methods LPP and LP: a) CAU100; b) CAU75; c) CAU50; d) CAU25; and e) QUARTZ. [Figura 6: Correlação entre os métodos de difração a laser LPP e LP: a) CAU100; b) CAU75; c) CAU50; d) CAU25; e e) QUARTZ.] 
Table V - Statistical analysis for correlation between densimeter and LPP methods.

[Tabela $V$ - Análise estatística para correlação entre os métodos do densímetro e difração a laser.]

\begin{tabular}{|c|c|c|c|c|c|}
\hline Statistical analysis & CAU100 & CAU75 & CAU50 & CAU25 & QUARTZ \\
\hline $\mathrm{S} 1$ & 186.16 & 133.74 & 76.81 & 49.69 & 62.02 \\
\hline S2 & 312.61 & 322.04 & 272.05 & 420.59 & 251.31 \\
\hline $\mathrm{S} 1 / \mathrm{S} 2-\mathrm{F}_{\text {calculated }}{ }^{*}$ & 1.68 & 2.40 & 3.54 & 8.46 & 4.05 \\
\hline $\mathrm{F}_{\text {tabulated }}(5 \%)$ & 4.84 & 4.84 & 4.84 & 4.84 & 4.84 \\
\hline $\mathrm{HO}$ & Accepted & Accepted & Accepted & Rejected & Accepted \\
\hline H1 & Rejected & Rejected & Rejected & Rejected & Rejected \\
\hline Conclusion & $\begin{array}{l}\text { Densimeter } \\
=\text { laser } \\
\text { diffraction }\end{array}$ & $\begin{array}{l}\text { Densimeter } \\
\quad=\text { laser } \\
\text { diffraction }\end{array}$ & $\begin{array}{c}\text { Densimeter }= \\
\text { laser diffraction }\end{array}$ & $\begin{array}{c}\text { Densimeter } \neq \\
\text { laser diffraction }\end{array}$ & $\begin{array}{c}\text { Densimeter }= \\
\text { laser diffraction }\end{array}$ \\
\hline
\end{tabular}

between the variables analyzed. These results were in line with the comparisons between the granulometric curves previously described and those obtained through analysis of variance that indicated no statistical differences between the data obtained; in other words, the sample preparation did not influence the results obtained by this method.

Results of the analysis of variance between the densimeter and LPP methods: this analysis was done taking into consideration the sample preparation for both techniques. In Table V, the statistical results of the analysis of variance are presented, with the objective of evaluating the interrelation of the methods under study. All tests were performed at a significance level of $\alpha=5 \%$. In a simple manner, the analysis of variance tests the null hypothesis of representativeness of the model to explain the phenomenon. The results presented for compositions CAU100, CAU75, CAU50, and QUARTZ compared the property for the two methods and proved that there was no statistical difference between either method of particle size analysis under study. The $\mathrm{F}_{\text {calculated }}$ values, measured from the model variance ratio, were smaller than the values in the Fisher-Snedecor table for 11 degrees of freedom; so, within the acceptance region for the null hypothesis (H0) with a confidence of $95 \%$, these methods reproduced the same result. For the CAU25 composition, the null hypothesis was rejected, since the $\mathrm{F}_{\text {calculated }}$ was greater than the $\mathrm{F}_{\text {tabulated }}$, therefore placing it within the rejection region.
Analysis of variance of results for LPP and LP methods: Table VI presents the statistical results of the analysis of variance to evaluate the interrelation of the methods under study. All tests were performed at a significance level of $\alpha=5 \%$. A joint analysis of the variance tables for the laser diffraction methods with and without sample preparation showed that in all of the studied cases, the null hypothesis was accepted. This indicated that, from a statistical point of view, sample preparation did not influence the granulometric analysis results by laser diffraction for the compositions under study. The $\mathrm{F}_{\text {calculated }}$ values measured from the model variance ratio were smaller than the values in the FisherSnedecor table for 99 degrees of freedom, so they fell within the acceptance range with a confidence of $95 \%$. This result confirmed what was already expected, based on the similarity seen between the granulometric distribution curves for the laser methods with and without sample preparation. This study presented a more reliable assessment compared with the analysis of variance between the sedimentation and laser diffraction methods, as a larger sample size usually leads to a better estimate of the populational parameter.

Some authors [23, 24] compared the granulometric analysis methods quantitatively through analysis of variance. One study [23] evaluated the methods of sieving and densimetry for soil samples and verified that sedimentation quantified more accurately the sand, silt, and clay fractions, agreeing with the results obtained among the studied

Table VI - Statistical analysis for correlation between LPP and LP methods.

[Tabela VI - Análise estatística para correlação entre os métodos LPP e LP.]

\begin{tabular}{cccccc}
\hline Statistical analysis & CAU100 & CAU75 & CAU50 & CAU25 & QUARTZ \\
\hline $\mathrm{S} 1$ & 855.84 & 914.06 & 853.95 & 973.63 & 920.91 \\
$\mathrm{~S} 2$ & 894.76 & 788.89 & 758.1 & 655.13 & 577.21 \\
$\mathrm{~S} 1 / \mathrm{S} 2-\mathrm{F}_{\text {calculated }}$ & 1.04 & 1.15 & 1.12 & 1.48 & 1.59 \\
$\mathrm{~F}_{\text {tabulated }}(5 \%)$ & 3.94 & 3.94 & 3.94 & 3.94 & 3.94 \\
$\mathrm{H} 0$ & Accepted & Accepted & Accepted & Accepted & Accepted \\
$\mathrm{H} 1$ & Rejected & Rejected & Rejected & Rejected & Rejected \\
Conclusion & LPP $=$ LP & LPP $=$ LP & LPP $=$ LP & LPP $=$ LP & LPP $=$ LP \\
\hline
\end{tabular}


methods. Another study [24], in turn, compared the methods of image analysis and laser diffraction through analysis of variance, and found no statistical difference between these methods. Regarding the textural classification of the studied compositions, differences between the clay, silt, and sand fractions for the evaluated methods were identified, mainly due to the differences between the physical principles used by the techniques to obtain the spherical particle diameter, which determines the final analysis result. The densimeter method was the most accurate in its fraction quantification, having a higher sensitivity in identifying the clay fraction. The laser diffraction method, in turn, underestimated the clay fraction and overestimated the silt fraction, which was higher for the method without sample preparation. The sand fraction was underestimated for all analyzed methods. Other studies point out that the sand fraction does not show drastic variations from one method to the other. However, it was possible to visualize that, depending on the size of the sandy particles present in the soil, this may be subject to alteration. The quartz used in the study compositions represented the sandy fraction of the soil, and should, therefore, be identified as such. The correlation was performed using the linear correlation coefficient (R) obtained by linear regression between the cumulative volumes of each method under study. This indicated a strong relationship between the results of the densimeter and laser diffraction methods with sample preparation and a very strong relationship between the laser diffraction methods with and without preparation.

\section{CONCLUSIONS}

The comparison between the laser diffraction methods (with and without standardized sample preparation) indicated that statistically there was no difference between these methods. The comparison between the densimeter and laser diffraction methods, both with standardized sample preparation, reported the same results, except for composition CAU25 (25\% kaolin+75\% quartz). The dispersion plots obtained through linear regression indicated the fit of the model for the variables under study and the correlation coefficient between them. It showed a strong correlation between the densimeter method and the laser diffraction method with sample preparation, and a very strong correlation between the laser methods with and without preparation, with $95 \%$ confidence. In general, it can be stated that the results related to the cumulative volume of the particle size distribution are statistically the same, regardless of the method used. From this, it can be inferred that the sample preparation for the laser method did not significantly interfere with the results obtained.

\section{REFERENCES}

[1] C.J. Papini, R.M. Leal Neto, in $16^{\text {th }}$ Braz. Congr. Mater. Eng. Sci., Porto Alegre (2004) 10531.

[2] B.M.A. Brito, J.M. Cartaxo, G.A. Neves, H.C. Ferreira, in $59^{\text {th }}$ Braz. Ceram. Congr., Barra dos Coqueiros (2015).

[3] R.M.F. Lima, J.A.M. da Luz, Rev. Esc. Minas 54, 2 (2001).

[4] P.E.R. Araújo, A.B. Martins, H.S. Ferreira, S.M.L. Silva, H.C. Ferreira, in 52 ${ }^{\text {nd }}$ Braz. Ceram. Congr., S. Paulo (2008).

[5] J.A. Jorge, J.L. de Paula, J.R.F. Menk, Pesq. Agrop. Bras. 7, 20 (1985) 865.

[6] T. Allen, Particle size measurement, Chapman Hall, Londres (1973).

[7] J.C. Cunha, M.G.B.S. Freire, H.A. Ruiz, R.B.A. Fernandes, V.H. Alvarez, Rev. Bras. Eng. Agríc. Amb. 20 (2014) 783.

[8] NBR 7181, "Solo - análise granulométrica”, Ass. Bras. Norm. Técn., Rio Janeiro (1984).

[9] R.A. Dantas, Engenharia de avaliações: uma introdução a metodologia cientifica, Pini, S. Paulo (1998).

[10] S.P. da Silva, "Caulim”, Balanço Miner. Bras., Ag. Nac. Miner., Brasil (2001).

[11] I.O. Araújo, A.G. de Souza, I.M.G. dos Santos, M.R. do Nascimento, Cerâm. Ind. 17, 2 (2012) 36.

[12] A.B. de Carvalho Júnior, T.F. Barros, P.L. Guzzo, H.J. Khoury, Mater. Res. 15, 4 (2012) 536.

[13] J.N. Ferreira, J.M. Cogo, I.S. Mello, M.A. Carvalho, R.A.R. Silva, D.L. Guerra, in $50^{\text {th }}$ Braz. Chem. Congr., Cuiabá, (2010).

[14] J.P. Bardet, Experimental soil mechanics, Prentice Hall, New York (1997).

[15] B. Wen, A. Aydin, N.S. Duzgoren-Aydin, Geotechn. Test. J. 25, 4 (2002) 434.

[16] K.A. Smith, C.E. Mullins, Soil and environmental analyses, Marcel Dekker, New York (2000).

[17] F.M. Barreiros, P.J. Ferreira, M.M. Figueiredo, Part. Part. Syst. Charact. 13, 1 (1996) 368.

[18] C. Di Stefano, V. Ferro, S. Mirabile, Biosyst. Eng. 6, 1 (2010) 205.

[19] M.K. Sato, R.S. Guedes, H.V. de Lima, A.R. Fernandes, A.M.S. Braz, Ciênc. Agrár. 58, 1 (2015) 90.

[20] V. Ramaswamy, P.S. Rao, J. Coast. Res. 22, 4 (2006) 1000 .

[21] L. Beuselinck, G. Govers, J. Poesen, G. Degraer, L. Froyen, Catena 32, 1 (1998) 193.

[22] D. Goossens, Sedimentology 55, 1 (2008) 65.

[23] F.O. Nobile, H.D. Nunes, V.O. Baldocchi, Holos Environ. 14, 2 (2014) 162.

[24] P.D.B. Guilherme, C.A. Borzone, M.L. Bueno, M.R. Lamour, Braz. J. Aquat. Sci. Technol. 2, 19 (2015) 23.

(Rec. 08/10/2018, Rev. 01/02/2019, 09/03/2019, Ac. 10/03/2019) 